\title{
Knowledge Management and Reuse in Virtual Learning Communities
}

\author{
https://doi.org/10.3991/ijet.v14i16.10588 \\ Sekkal Houda $\left({ }^{\varpi}\right)$ \\ Mohammed V University, Rabat, Morocco \\ houda.sekkal@gmail.com \\ Amrous Naila \\ Mohammed V University, Rabat, Morocco \\ Ecole des Sciences de l'Information (ESI), Rabat, Morocco \\ Bennani Samir \\ Mohammed V University, Rabat, Morocco
}

\begin{abstract}
One of the main sources of knowledge in the web is the social networks and especially online communities because they contain human experiences which are considered as a rich source of information. This knowledge is in the most cases unstructured and is in the form of discussions organized generally by topics. If that knowledge could be represented and stored in order to be reused, it would facilitate the knowledge acquisition by members. The present paper tries to analyze the studies that treat the question of extracting and managing knowledge in Online Learning Communities based on several criteria exposed all along this paper. Then we propose a framework for managing knowledge in Virtual Learning communities inspired from the different previous frameworks presented in the analyzed studies, and try to propose and approach to overpass the different challenges present in the actual knowledge Management processes of Virtual Communities. This article presents a new way for managing knowledge in online communities in particular and user-generated content in general by the integration of automated approaches. The proposed framework can be considered as a way to enhance learning through online communities and a medium to extract knowledge produced by the collective intelligence of groups.
\end{abstract}

Keywords-Knowledge reuse, knowledge management, online communities, social media, knowledge extraction.

\section{Introduction}

The wide development and spread of Social Media have influenced every aspect of our human life. Social Media (SM) has become a real source of information and knowledge that one can uses in his daily life. Whether if we are looking for the world news or looking for a good restaurant to take lunch, social media provide us with the 
information desired based on previous experiences and reviews shared by other members in the social networks.

One of the aspects that are influenced by the emergence of SM is the learning process. According to Carr [1] "studies show that social media has the potential to offer an alternative pedagogical approach in integrating formal and informal learning and can enhance self-regulated learning among students in formal education". The same author report that in recent years, social media has been positioned as a learning tool.

Social Media provide many attractive services to enhance communication between members such as the creation of online communities of practice. Wenger [2] considers a community of practice as "a group of people who share an interest in a domain of human endeavor and engage in a process of collective learning that creates bonds between them".

Many types of online communities exist depending on the goal of the community and the domain of interest. In the context of learning, a group of members may constitute an online learning community. Communities of learning are self-organizing systems of informal learning [3]. In social media, communities of practice created are qualified as virtual communities of practice. According to Curran et al. [4] and [5] a virtual Community of Practice (VCoP) is a network of individuals who share a domain of interest about which they communicate online.

In a community of practice, learning process between members can occur by asking questions to other members and learn from the answers and personal experiences shared which represent a real source of knowledge. Fulton and Riel [6] define a learning community as "A group of people who share a common interest in a topic or area, a particular form of discourse about their phenomena, tools and sensemaking approaches for building collaborative knowledge, and valued activities".

Members of Virtual Learning Communities (or online learning communities) need technological support in order to facilitate their learning activities (e.g. during a problem-solving process). One of the most important challenges of such communities is to enhance the knowledge exchange and sharing among the different members.

Virtual learning communities in social media contains rich content produced through interactions like question answering content and documents shared that represent a real source of knowledge in the specific domain of interest of the community. This knowledge is not capitalized or structured and its access and reusability by a learner is difficult. If a member wants to benefit from the ideas and the knowledge generated by the online community, the only existing solution is to read everything written and to filter the relevant information manually [7]. In order to facilitate its access and reusability by learners and members interested in that field, this paper propose a framework of knowledge management and reuse in the virtual learning community. For this purpose, the paper investigates at first studies done by researchers to tackle the problem of knowledge reuse in virtual learning communities in social media and then propose a framework that foster knowledge Management and reuse in online communities in order to promote learning in such communities.

This paper is organized as follows: The first section discusses the main concepts and background related to knowledge management and reuse in online communities. 
The second section presents the analysis of previous works done in relation with our research problem. The third section describes our proposed approach for knowledge management and reuse in online learning communities. This paper concludes with a discussion on the challenges facing knowledge management in online communities and recommendations to enhance it.

\section{Background}

\subsection{Knowledge management}

Before defining Knowledge Management, let us first present what knowledge is. There are many authors who proposed definitions of the term "knowledge", we present here one of the definitions which is given by Davenport and Prusak [8]: knowledge "is a fluid mixture of condensed experience, values, context information and experimental insight, that offers a structure for evaluation and incorporation of new experiences and information". Nonaka et al. [9] pointed the social aspect of knowledge by reporting that knowledge is dynamic, since it is created in social interactions amongst individuals and organizations. Generally, there are two forms of knowledge: tacit knowledge and explicit knowledge [10]. Tacit knowledge is hard to formalize and communicate where the explicit knowledge can be easily collected, organized and transferred through digital means and can be found on documents, books or softwares [11]. Knowledge management aims at capturing, transferring, and reusing knowledge [12]. One of the most challenges of Knowledge Management is the formalization and capitalization of tacit knowledge. De Lima, Carvalho and Ambrósio [11] reported that the main objective of Knowledge Management, in the context of organizations, is to enhance an enterprise's performance and that of its workers, not simply by sharing knowledge, even though this is a valuable sub product of the process, but through the identification, capture, validation and knowledge transference. In our case, knowledge management can be seen as a solution to enhance learning between members of an online community through the identification, capture, validation and reuse of the knowledge shared.

In order to implement a knowledge management system, it is important to understand first the context and steps of the knowledge creation process. Nonaka and Takeuchi [13] in there SECI ${ }^{1}$ Model represented the process of knowledge creation by describing the interaction between tacit and explicit knowledge until the creation of knowledge between two actors [14]. In the SECI Model (figure 1), an organization creates knowledge through the interactions between explicit knowledge and tacit knowledge [9].

The model proposes four modes of knowledge conversion (i.e the interaction between tacit and explicit knowledge) which are: the socialization mode (from tacit knowledge to tacit knowledge); the externalization mode (from tacit knowledge to explicit knowledge); the combination mode (from explicit knowledge to explicit

\footnotetext{
${ }^{1}$ Socialisation, Externalization, Combination and Internalisation.
} 
knowledge); and finally, the internalization mode (from explicit knowledge to tacit knowledge) [9]. The SECI model shows again the social aspect of the knowledge creation process. In our context, online learning communities are among the environments where the SECI model is concretized. Hence, the knowledge created by the community must be reused by learners to enhance learning.

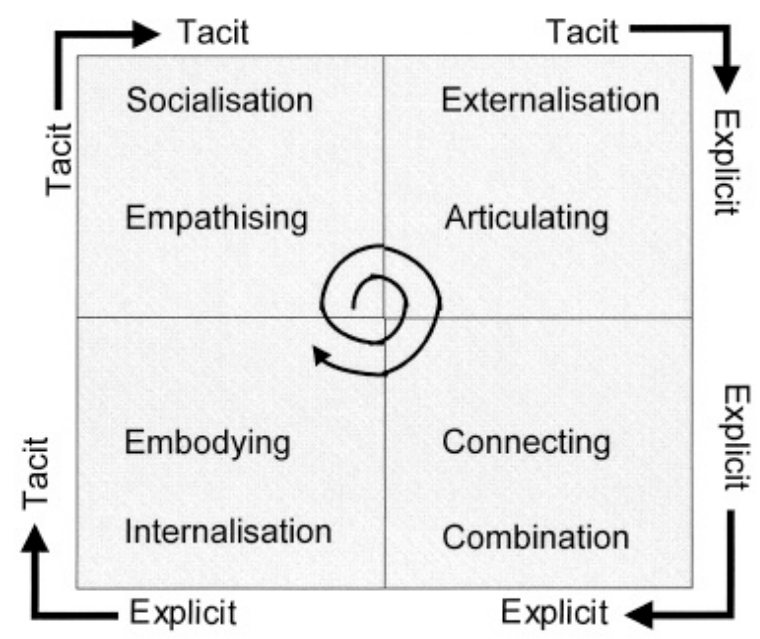

Fig. 1. The SECI Process, from SECI, Ba and Leadership: a United Model of Dynamic Knowledge Creation, 2000

\subsection{Knowledge reuse}

According to Mihindu et al. [15], the knowledge related processes such as; knowledge creation, identification, storage, valuation, sharing, transfer, acquisition, community learning, distribution, dissemination, etc. are all very much interdependent Knowledge Management (KM) procedures that each community member or group act and react to on a daily basis. Sandkuhl [14] addressed the question of knowledge reuse by representing it in the context of areas from knowledge management and knowledge engineering. He presented questions related to knowledge processes such as: how to identify knowledge? How to store knowledge? How to apply knowledge? How to share knowledge? How to evaluate knowledge? The author localized the Knowledge reuse phase between the application and sharing of knowledge. On the other hand, Davenport et al. [8] categorized Knowledge processes into two principal categories: knowledge creation (as in research or new product development) and knowledge reuse (as in sharing best practices or helping others solve common technical problems).

Markus [16] identified four different types of knowledge reuse situations that include shared work producers, shared work practitioners, expertise seeking novices, and secondary knowledge miners. The same author presented a definition on the knowledge reuse process (figure 2) where knowledge reuse is described in terms of 
the following stages: capturing or documenting knowledge, packaging knowledge for reuse, distributing or disseminating knowledge (providing people with access to it), and reusing knowledge.

Our work is focused on the knowledge reuse process. It consists on the analysis of the previous works conducted in the area of knowledge management and reuse in virtual communities. Our analysis is conducted by comparing Markus knowledge reuse process (figure 2) with the approaches proposed by the different authors of articles (table 1) on knowledge management in online communities.

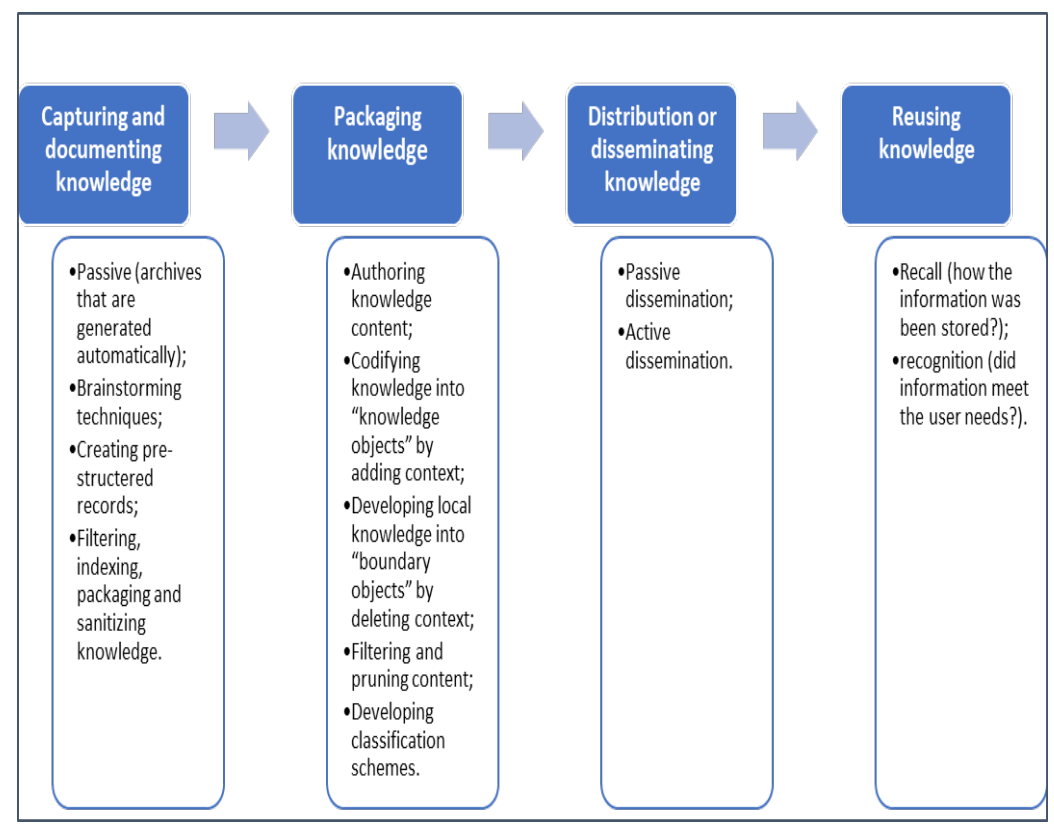

Fig. 2. The knowledge reuse process according to Markus (2001)

\subsection{Virtual learning community of practice}

Learning community of practice is a group of people who actively learn from each other, whether as a formal or informal activity [17]. There are several characteristics of a Community of Practice [23]:

- The domain: The topic that creates and sustains interest

- The community: That people join to further develop their interest

- The practice: The application of the ideas or activities in their life or work

In the age of Web 2.0 where the user is at the same time content reader and generator, the term 'virtual community' appeared. Howard Rheingold [26] described it as a "social aggregations that emerge from the Internet when enough people carry on public discussions long enough and with sufficient human feeling to form webs of personal relationships in cyberspace". Web 2.0 enable users not only to create and 
share information but also to convert it to knowledge [25]. In communities of practice, members use the knowledge shared to solve their own problems and share the solution with the community. Those interactions contribute in the growth of the knowledge in the community and become more attractive to new members [11]. According to Lima [11], the management of knowledge acquired or developed by the community must be indexed and stored as to be easily retrieved and reused.

In the context of learning within a community of practice, knowledge management and specially knowledge reuse will enable to enhance the learning process by the identification, capture and validation of knowledge present in the community's content and interactions in order to facilitate its reuse by learners.

To sum up the above-mentioned points and to categorize our work, our first contribution is to conduct a comparative analysis of the different works conducted by researchers to deal with the question of managing content and knowledge shared in online communities by comparing their approaches with the Markus knowledge reuse process [16]. Our second contribution is to propose an approach of knowledge reuse and management that enables members of an online learning community to reuse and benefit from previous shared and validated knowledge in the same community.

In the following section, we expose the main methods and techniques proposed by authors to tackle the question of knowledge management in Virtual communities.

\section{Comparative Analysis of Knowledge Management Approaches Based on Markus Knowledge Reuse Process}

Many studies in the literature have focused their interest on the Knowledge Management in Virtual communities. This paragraph shed light on the major studies done on this area by presenting a comparative study based on the knowledge reuse process. The goal is to explore techniques and approaches proposed by the authors to solve the problem of managing knowledge in Virtual Learning Communities.

The approach used to classify studies as mentioned above is based on the knowledge reuse process proposed by Markus [16] (figure 2).

\subsection{The knowledge reuse process}

The Figure 2 presents the process of knowledge reuse proposed by Markus [16]. This process is composed of four stages that allow reusing knowledge. The first stage consists on capturing and documenting knowledge. According to Markus, this stage occurs in at least four ways as mentioned in figure 2 :

Passive documenting and capture of knowledge by automatically generating archives about a work process by the group work.

Documenting knowledge by a structure such as facilitators using for example brainstorming techniques.

Documenting knowledge by producing pre-structured records in the context of a knowledge reuse strategy. 
Documenting knowledge may also occur in the context of a strategy of filtering, indexing, packaging and sanitizing knowledge for later use.

The second stage of the knowledge reuse process concerns packaging knowledge. It consists of organizing documents generated by the documentation and capture stage by culling, cleaning and polishing, structuring, formatting, and/or indexing documents with respect of a classification scheme. The third stage of the process of knowledge reuse is the dissemination of knowledge, which can be passive or active. Passive dissemination is when the user is asked to browse the information structured and stored in the previous steps. Active dissemination concerns the fact of "pushing" information to the user. The final stage is reusing knowledge by applying the recall and the recognition of the information stored as mentioned in the figure 2.

The author also add that the reusing of knowledge stage consists of the following steps:

- Defining the search question

- The search for, and location of, experts or expertise

- Selection of an appropriate expert or of expert advice

- Applying the knowledge

Markus [16] also add three roles of the process of knowledge reuse which are: the "knowledge producer who is the originator and documenter of knowledge, who records explicit knowledge or makes tacit knowledge explicit. Knowledge intermediary prepares knowledge for reuse by eliciting it, indexing it, summarizing it, sanitizing it, packaging it, and who performs various roles in dissemination and facilitation. Knowledge consumer who is the knowledge reuser, who retrieves the knowledge content and applies it in some way." [16]. In the following section, we present the comparative analysis conducted on the studies that propose approaches for knowledge management and reuse based on the above-mentioned process.

\subsection{Comparative analysis of knowledge management approaches}

Data collection: The first step of our analysis approach is to collect papers that treat the concerned research area which is: knowledge management and reuse in virtual learning communities. We applied queries in some digital libraries and search engines like: Google Scholar, ACM Digital Librairy, IEEE Xplore Digital Librairy and journals specialized in knowledge management like Journal of Knowledge Management and International Journal of Knowledge Engineering and Data Mining. We collected articles that we filtered based on their relevance to our research area and their publication year. Only article that are published between 2010 and 2018 were selected. We build our final collection of relevant articles as presented in the table 1. 
Table 1. The list of articles selected for the analysis

\begin{tabular}{|l|l|c|l|}
\hline & \multicolumn{1}{|c|}{ Title } & Publication Year & \multicolumn{1}{|c|}{ Journal/Conference } \\
\hline 1 & $\begin{array}{l}\text { A process for knowledge reuse in communities } \\
\text { of practice of e learning. [12] }\end{array}$ & 2010 & $\begin{array}{l}\text { Procedia Social and Behavioral } \\
\text { Sciences }\end{array}$ \\
\hline 2 & $\begin{array}{l}\text { Semantics and knowledge capitalization in } \\
\text { online communities of practice of e-learning. } \\
{[18]}\end{array}$ & 2011 & $\begin{array}{l}\text { In Proceedings of the } \\
\text { International Conference on } \\
\text { Knowledge Management and } \\
\text { Information Sharing }\end{array}$ \\
\hline 3 & $\begin{array}{l}\text { Automatic Extraction of Advice-revealing } \\
\text { Sentences for Advice Mining from Online } \\
\text { Forums. [19] }\end{array}$ & 2013 & K-CAP '13 \\
\hline 4 & Finding Informative Q\&As on Twitter. [20] & 2014 & WWW'14 \\
\hline 5 & $\begin{array}{l}\text { Distilling Task Knowledge from How-To } \\
\text { Communities. [21] }\end{array}$ & 2017 & WWW 2017 \\
\hline 6 & $\begin{array}{l}\text { Mining online community data: The nature of } \\
\text { ideas in online communities. [7] }\end{array}$ & 2017 & $\begin{array}{l}\text { Journal: Food Quality and } \\
\text { Preference }\end{array}$ \\
\hline
\end{tabular}

The comparative analysis: In our collection of articles presented in table 1, we notice that there are two categories of studies: a first category of studies that propose a complete process for knowledge reuse in online community of practice containing all the steps proposed by Markus [16]. The second category of studies presents an approach for the extraction of knowledge in online community. The table 2 lists the two categories of studies.

Table 2. Categories of studies analyzed

\begin{tabular}{|l|l|}
\hline \multicolumn{1}{|c|}{ Category 1 } & \multicolumn{1}{c|}{ Category 2 } \\
\hline $\begin{array}{l}\text { Article 1: A process for knowledge reuse in } \\
\text { communities of practice of e-learning }\end{array}$ & $\begin{array}{l}\text { Article 3: Automatic Extraction of Advice-revealing } \\
\text { Sentences for Advice Mining from Online Forums }\end{array}$ \\
\hline $\begin{array}{l}\text { Article 2: Semantics and knowledge capitalization in } \\
\text { online communities of practice of e-learning }\end{array}$ & Article 4: Finding Informative Q\&As on Twitter \\
\hline & $\begin{array}{l}\text { Article 5: Distilling Task Knowledge from How-To } \\
\text { Communities }\end{array}$ \\
\hline & $\begin{array}{l}\text { Article 6: Mining online community data: The nature } \\
\text { of ideas in online communities }\end{array}$ \\
\hline
\end{tabular}

Analysis and comparison of the category 1 of articles: The category 1 contains articles that propose a process composed of different steps for knowledge reuse in communities of practice. Table 3 summarizes the research question and contributions of the two articles of the category 1 .

Table 3. Research questions and contributions of papers of the category 1

\begin{tabular}{|c|l|l|l|}
\hline Article & \multicolumn{1}{|c|}{ Research question } & \multicolumn{1}{|c|}{$\begin{array}{c}\text { The community } \\
\text { analyzed }\end{array}$} & \multicolumn{1}{c|}{ Contribution of the paper } \\
\hline Article 1 & $\begin{array}{l}\text { What is the knowledge to reuse } \\
\text { and what is the best approach } \\
\text { for its representation? } \\
\text { How to make adaptive the } \\
\text { knowledge access according to } \\
\text { members profiles? }\end{array}$ & $\begin{array}{l}\text { Community of } \\
\text { professionals in e- } \\
\text { learning }\end{array}$ & $\begin{array}{l}\text { Proposes a process for knowledge reuse } \\
\text { within a CoPE composed of the } \\
\text { following steps: } \\
\text { Reification process transforming Tacit } \\
\text { and Elicit knowledge to A new Elicit } \\
\text { Knowledge; }\end{array}$ \\
\hline
\end{tabular}




\begin{tabular}{|l|l|l|l|}
\hline & $\begin{array}{l}\text { How to enrich this knowledge } \\
\text { with members' intentions? }\end{array}$ & $\begin{array}{l}\text { An indexing process making reusable } \\
\text { the previous resulted knowledge. Two } \\
\text { knowledge-indexing techniques are } \\
\text { used: (a) Knowledge Annotation, using } \\
\text { the concepts of O'CoPE ontology } \\
\text { (ontology of the community of practice } \\
\text { in e-learning) (b) Knowledge } \\
\text { internationalization using members } \\
\text { intentions. }\end{array}$ \\
\hline Article 2 & $\begin{array}{l}\text { How to Capitalizing } \\
\text { knowledge for reuse in CoPEs? }\end{array}$ & $\begin{array}{l}\text { Community of } \\
\text { professionals in e- } \\
\text { learning }\end{array}$ & $\begin{array}{l}\text { Ontology-based framework for } \\
\text { capitalizing knowledge for reuse in } \\
\text { CoPEs. } \\
\text { Capitalize the tacit knowledge owned } \\
\text { by members of a CoPE, using semantic } \\
\text { annotations. }\end{array}$ \\
\hline
\end{tabular}

In order to compare the processes developed by the studies in table 3, we addressed a table (table 4) that exposes the comparison between the process presented by the different authors and the process of Markus [16]:

Table 4. Comparative analysis between the category 1 of articles and the knowledge reuse process of Markus (2001)

\begin{tabular}{|c|c|c|c|c|}
\hline & \multicolumn{4}{|c|}{ The knowledge reuse process presented by Markus (2001) } \\
\hline & $\begin{array}{l}\text { Capturing and } \\
\text { documenting } \\
\text { knowledge }\end{array}$ & $\begin{array}{l}\text { Packaging } \\
\text { knowledge }\end{array}$ & $\begin{array}{l}\text { Disseminating } \\
\text { knowledge }\end{array}$ & Reusing knowledge \\
\hline $\begin{array}{l}\text { Steps of the } \\
\text { Process presented } \\
\text { by the Article } 1\end{array}$ & $\begin{array}{l}\text { Knowledge } \\
\text { conversion from } \\
\text { tacit to explicit } \\
\text { knowledge through } \\
4 \text { modes: } \\
\text { Socialization, } \\
\text { Externalization, } \\
\text { Combination, and } \\
\text { Internalization } \\
\text { (inspired from the } \\
\text { SECI schema) } \\
\text { which are combined } \\
\text { in a knowledge } \\
\text { reification process. }\end{array}$ & $\begin{array}{l}\text { Use ontologies to } \\
\text { create a shared } \\
\text { vocabulary: } \\
\text { knowledge } \\
\text { annotation }\end{array}$ & $\begin{array}{l}\text { Adaptation process: } \\
\text { the goal is to adapt } \\
\text { knowledge to } \\
\text { members' profiles } \\
\text { such as Academic } \\
\text { background and } \\
\text { Working experience }\end{array}$ & $\begin{array}{l}\text { Knowledge } \\
\text { internationalization: } \\
\text { aims to show the } \\
\text { expected goals of the } \\
\text { knowledge reuse } \\
\text { process. }\end{array}$ \\
\hline $\begin{array}{l}\text { Steps of the } \\
\text { Process presented } \\
\text { by the Article } 2\end{array}$ & $\begin{array}{l}\rightarrow \text { Knowledge is } \\
\text { elicited from } \\
\text { members through } \\
\text { discussion using the } \\
\text { annotation process } \\
\text { (e.g. analysis } \\
\text { comments). } \\
\rightarrow \text { Filtering and } \\
\text { validation of } \\
\text { knowledge through } \\
\text { discussion and } \\
\text { annotations and } \\
\text { comments. }\end{array}$ & $\begin{array}{l}\text { representing } \\
\text { knowledge via } \\
\text { ontologies. }\end{array}$ & $\begin{array}{l}\text { A knowledge } \\
\text { resource search } \\
\text { service is provided } \\
\text { to recommend high } \\
\text { quality content to } \\
\text { members based on } \\
\text { their profiles and } \\
\text { needs. }\end{array}$ & $\begin{array}{l}\rightarrow \text { Storage via } \\
\text { organizational } \\
\text { learning memory } \\
\rightarrow \text { Reuse trough } \\
\text { mining and } \\
\text { visualization of } \\
\text { knowledge in problem } \\
\text { solving. }\end{array}$ \\
\hline
\end{tabular}


We notice, according to the table 4 , that the authors handled all the steps of knowledge reuse presented by Markus [16] from capturing and documenting knowledge to reusing it. The first article (article 1 in the table 4) presents a process inspired from the SECI process for capturing and reification of knowledge. The same article proposed an ontology for the representation and the organization of information and knowledge shared by members and suggested an adaptation process in order to maximize the usefulness of knowledge shared between members as detailed in the table 4 . The second article (article 2 in the table 4) presents a process for capitalizing knowledge in the community based on member's comments and discussions using ontologies also. The article proposes an annotation model for the capitalization of tacit knowledge. These annotations are based on user's comments.

Analysis of the category 2 of articles: Articles in table 5 present approaches to extract knowledge from online community and do not propose a complete process for knowledge management and reuse as presented by Markus [16]. The approaches presented by the articles (table 5) uses new technologies like machine learning applications and knowledge base creation to automatically extract knowledge from these communities.

Table 5. Research questions and contributions of papers of the category 2

\begin{tabular}{|c|c|c|c|}
\hline Article & Research questions & $\begin{array}{c}\text { The community } \\
\text { analyzed }\end{array}$ & Contributions of the paper \\
\hline Article 3 & $\begin{array}{l}\text { How to Provide travelers with } \\
\text { advice extracted from web travel } \\
\text { forums? }\end{array}$ & $\begin{array}{l}\text { Members of a Web } \\
\text { travel forum }\end{array}$ & $\begin{array}{l}\text { Provide a methodology to extract } \\
\text { advice-revealing sentences from } \\
\text { web forums with a proposition of } \\
\text { tree types features: syntactic, } \\
\text { context and semantic features to } \\
\text { detect Advice or Non-advice } \\
\text { sentences. }\end{array}$ \\
\hline Article 4 & $\begin{array}{l}\text { Find out: If social media data cover } \\
\text { a wide range of topics as existing } \\
\text { CQA services? } \\
\text { Is there a framework to extract high- } \\
\text { quality Q\&A content from the } \\
\text { massive amount of unstructured and } \\
\text { heterogeneous social media data? }\end{array}$ & $\begin{array}{l}\text { A community in } \\
\text { Yahoo! Forums and } \\
\text { Twitter }\end{array}$ & $\begin{array}{l}\text {-Find topics using Latent Dirichlet } \\
\text { Allocation. } \\
\text {-Extract high quality content using } \\
\text { the following classifiers in order to } \\
\text { classify informative Questions and } \\
\text { answers: Support Vector Machine, } \\
\text { Neural Network, and Random } \\
\text { Forest (RF) }\end{array}$ \\
\hline Article 5 & $\begin{array}{l}\text { How to automatically construct a } \\
\text { formal knowledge base on tasks and } \\
\text { task-solving steps, by tapping the } \\
\text { contents of online communities such } \\
\text { as WikiHow? }\end{array}$ & wikihow community & $\begin{array}{l}\text { Construction of a knowledge base } \\
\text { about the how to tasks by: } \\
\text {-information extraction from } \\
\text { wikihow } \\
\text {-Organization of the knowledge } \\
\text { base via clustering and hierarchical } \\
\text { techniques. }\end{array}$ \\
\hline Article 6 & $\begin{array}{l}\text { How to detect ideas from online } \\
\text { communities } \\
\text { automatically? }\end{array}$ & $\begin{array}{l}\text { Members of two } \\
\text { firm free online } \\
\text { com- } \\
\text { Munity }\end{array}$ & $\begin{array}{l}\text { Generate machine-learning } \\
\text { classifiers based on Support Vector } \\
\text { Machines and Partial Least Squares } \\
\text { that can detect ideas from each } \\
\text { respective online community. }\end{array}$ \\
\hline
\end{tabular}


To compare the contributions of the studies presented in table 4, we address a table that presents a comparison between them and the process of knowledge reuse [16] in order to situate the methods proposed in the Markus process.

Table 6. Comparative analysis between the category 2 of articles and the knowledge reuse process of Markus (2001)

\begin{tabular}{|c|c|c|c|c|}
\hline & \multicolumn{4}{|c|}{ The knowledge reuse process presented by Markus (2001) } \\
\hline & $\begin{array}{l}\text { Capturing and } \\
\text { documenting } \\
\text { knowledge }\end{array}$ & $\begin{array}{l}\text { Packaging } \\
\text { knowledge }\end{array}$ & $\begin{array}{l}\text { Disseminating } \\
\text { knowledge }\end{array}$ & Reusing knowledge \\
\hline $\begin{array}{l}\text { Approach presented } \\
\text { by the Article } 3\end{array}$ & $\begin{array}{l}\text { Extract advice- } \\
\text { revealing sentences } \\
\text { from Web forums }\end{array}$ & $\begin{array}{l}\text { Classification of } \\
\text { data extracted: the } \\
\text { proposition of } \\
\text { different types of } \\
\text { features that can } \\
\text { characterize advice } \\
\text { and non-advice } \\
\text { revealing sentences. }\end{array}$ & $\begin{array}{l}\text { Passive } \\
\text { dissemination by } \\
\text { offering a search } \\
\text { tool in the } \\
\text { knowledge } \\
\text { repository. }\end{array}$ & $\begin{array}{l}\text { The extracted } \\
\text { sentences are stored } \\
\text { in a well-organized } \\
\text { knowledge } \\
\text { repository }\end{array}$ \\
\hline $\begin{array}{l}\text { Approach presented } \\
\text { by the Article } 4\end{array}$ & $\begin{array}{l}\text { A framework to } \\
\text { automatically } \\
\text { extract informative } \\
\text { Q\&A content using } \\
\text { machine learning } \\
\text { techniques. }\end{array}$ & $\begin{array}{l}\text { Detection of the } \\
\text { Topic Coverage in } \\
\text { the community. }\end{array}$ & - & - \\
\hline $\begin{array}{l}\text { Approach presented } \\
\text { by the Article } 5\end{array}$ & $\begin{array}{l}\text { Extract tasks, } \\
\text { participants, } \\
\text { location and time } \\
\text { from a WikiHow }\end{array}$ & $\begin{array}{l}\text {-Grouping such } \\
\text { nearly synonymous } \\
\text { task frames together } \\
\text { can make the KB } \\
\text { more precise and } \\
\text { consistent. } \\
\text {-Clustering the task } \\
\text { frames } \\
\text {-taxonomy } \\
\text { construction and } \\
\text { hierarchical } \\
\text { clustering to } \\
\text { organize the } \\
\text { Knowledge base } \\
\text { tasks. }\end{array}$ & - & $\begin{array}{l}\text { - Tasks are stored in } \\
\text { the knowledge base. } \\
\text {-Semantically } \\
\text { organizing the } \\
\text { extracted task } \\
\text { phrases and their } \\
\text { candidate frames for } \\
\text { building a clean and } \\
\text { consistent KB. }\end{array}$ \\
\hline $\begin{array}{l}\text { Approach presented } \\
\text { by the Article } 6\end{array}$ & $\begin{array}{l}\text { Extraction and } \\
\text { classification of } \\
\text { ideas in online } \\
\text { community }\end{array}$ & $\begin{array}{l}\text { Classification of } \\
\text { knowledge: ideas } \\
\text { and non-ideas that } \\
\text { are in the form of } \\
\text { suggestions or } \\
\text { solutions. }\end{array}$ & - & - \\
\hline
\end{tabular}

According to table 6, all the articles expose a method for the extraction of many types of knowledge from online communities. The article 3 in the table proposes an approach to extract advices from communities and to store them in a knowledge repository. Article 4 proposes also a framework to extract informative questions and answers shared by the community and detect the topics covered. In the Article 5, the author exposes a technique for the extracting of tasks and task-solving steps present in 
an online community and storing of this knowledge in a knowledge base. The last article in the category 2 presents a system for the extraction and classification of ideas in online community.

All the above-mentioned articles propose approaches based on new technologies like machine learning techniques and natural language processing to extract many types of knowledge like advices, questions and answers, etc. Objectives of the studies were to mine and analyze the user-generated content in the communities in order to automate the response to predefined existing problems or to explore new ideas shared by members in these communities. Despite the contributions of each method presented in the table 6, none of the articles has presented its approach in the optic to reach a knowledge management and reuse goal. The integration of advanced techniques in the process of knowledge management and reuse in online-communities is essential with the growing volume of user-generated content. Especially in online learning communities were members, who are in the most cases learners, are seeking for high level and validated content and answers to their questions and problems. A framework for capitalization and reuse of the knowledge shared is needed to better answer learner's questions in the community. This will help fostering knowledge reuse and usefulness by members. To this aim, we propose our framework for knowledge management and reuse in Virtual learning communities in the next section.

\section{A Framework for Knowledge Management in Virtual Learning Communities}

Content shared in online learning Communities is mainly a user generated content. It may be in the form of text, images or videos. Our process concerns the text content. There are different types of content: questions, problem-solving tasks, tips and advices that are difficult to be reached due to the large volume of content generated by the community. This content is considered as a rich source of knowledge in the online learning community that has to be capitalized and reused by learners. The richness of the content shared and generated by the members of an online learning community lies in its added value or usefulness toward a problem or a question. If an asker asks a question about a problem in a particular domain, the members' right answers and suggestions could be of a great usefulness and become a source of knowledge for all the members. The capitalization and the management of that knowledge constitute our main goal in this section.

Our proposition is a process that enables knowledge management and reuse in online communities as shown in figure 3. The aim is to extract textual knowledge from user-generated content in the online community, to capitalize and store it in a well-organized knowledge base and enhance its reuse by an active dissemination of that knowledge. 


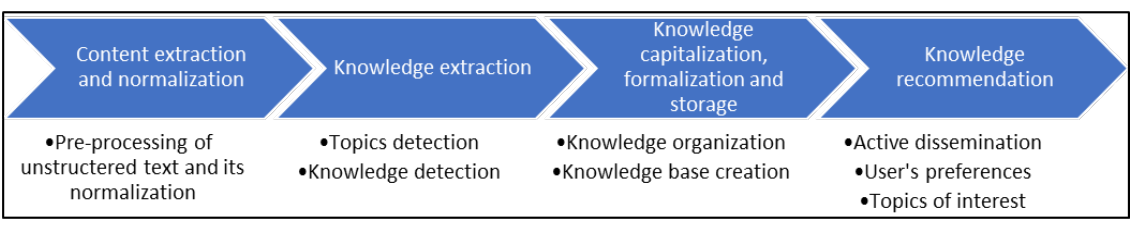

Fig. 3. a Framework for knowledge Management and reuse in online learning community

Content extraction and normalization: The first step of our process as shown in figure 3 is to extract the textual content from the community. The data extracted is unstructured and must be pre-processed. The pre-processing of text enables its normalization. The pre-processing of text is a step used in the Natural Language Processing ${ }^{2}$ field and consist on the normalization of text in order to converting it to a more standard and convenient form. The text normalization is composed of several steps: tokenization of words that concerns separating out words from the text, lemmatization which is the task of determining that two words have the same root, stemming that consist of stripping suffixes from the end of the word. The last step is sentence segmentation that consists of breaking up a text into individual sentences [22].

Knowledge extraction: After pre-processing the textual content of online community, the next step is the knowledge extraction. It consists on:

- Detecting the topics addressed by the community

- Detecting knowledge types in the community like question/answers, problemsolving recommendation, tips, and so on by analyzing the individual sentences extracted

- Detect the degree of informativeness of each sentence and its context (topic, authors, knowledge type, etc.)

Knowledge capitalization, formalization and storage: After the knowledge extraction step comes the knowledge capitalization and storage. The aim is to organize the knowledge extracted in a well-organized form as a knowledge base. This will also enable the users to search for a topic, make queries about a specific question or a problem and see all the previous answers and solutions shared solved by members about the same topic. The knowledge base construction will enhance the knowledge reuse by learners in the online-community by querying it.

Knowledge recommendation: Knowledge recommendation is an important step in the reuse process as it makes possible the active dissemination of knowledge. The knowledge recommendation is realized based on the collection and the storage of user's preferences such as topics of interest, profiles in order to propose the "right knowledge" to the right learner. The knowledge recommendation can be done by

\footnotetext{
2 According to Liddy [24], Natural Language Processing is a theoretically motivated range of computational techniques for analyzing and representing naturally occurring texts at one or more levels of linguistic analysis for the purpose of achieving human-like language processing for a range of tasks or applications.
} 
pushing knowledge to the user by sending notifications about a new knowledge extracted and capitalized by the knowledge base that can much the user interest. The user can then judge about the usefulness of each knowledge depending on it preferences.

To sum up what was said in this section, the proposed framework is a knowledge management and reuse framework that intends to benefit from the collective intelligence of a group of people in order to construct and promote a knowledge base shared among them. This knowledge is of a great importance that can enables quick problems solving and fields and ideas development.

\section{Discussion}

Online learning communities constitute a real pool of human knowledge that is important to manage to increase its utilization and reuse by learners. In our comparative analysis about studies applying a process of knowledge management in communities of practice, we noticed that approaches rely much more on the user participation and notification when it is about capitalizing knowledge for the reuse. The knowledge capture and capitalization by users is a labor task that is time consuming particularly when it concerns a large volume of textual data.

With the exponential increase of data volume shared in online communities, it is better to think about automated approaches to analyze and capitalize this content rather than human annotations and validation. We found that many studies propose automated approaches to extract knowledge from online communities without integrating it in a knowledge management strategy. Some projects, like [20], that concern automated approaches for knowledge extraction and capitalization, integrate machine-learning techniques when it's about classifying knowledge. These techniques have shown great results but still depending on human labor when it comes to training data, which can be tough and pricey toward large volume data.

It is important to integrate the automated approaches in a knowledge management process in order to accelerate the capitalization of knowledge. Thus, we proposed a knowledge management in online communities' process that integrate an automated knowledge extraction and capitalization step so as to ensure that all shared knowledge will be analyzed and capitalized. This automated step relies on natural language processing and classification techniques in order to extract informative sentences which represent knowledge.

Another issue concerns the increasing of knowledge reuse process in online communities. In the analyzed studies, reusing knowledge was treated by simply organizing, storing and visualizing knowledge, which is considered as a passive way to disseminate knowledge. Knowledge reusing step is very important in the knowledge management process as it enables not only the dissemination of knowledge among members, but also to validate it and to develop it through member's feedbacks and validations. In our proposed framework, the knowledge recommendation step will foster the reuse of knowledge shared by actively proposing 
knowledge that corresponds to the user (learner) needs. Here, information about a learner could be used to predict topics of interest of each on.

\section{Conclusion and Future Work}

One of the main sources of knowledge in the web is the social networks content and especially online communities. These Online communities contain a rich capital of human experiences considered as knowledge that members all over the world share. This knowledge is in the most of the cases in the form of discussions organized generally by topics. The knowledge shared by members in the online communities is unfortunately not structured and not capitalized. Many members try to access and learn from the shared knowledge in the community but cannot benefit from it due to its unstructured form. If that knowledge could be represented and stored in order to be reused, it would facilitate the knowledge acquisition by members. Our goal in this paper is to improve knowledge management and reuse in those communities. We conducted a comparative analysis of studies that treated knowledge management and extraction in online communities. The analysis was conducted based on Markus [16] knowledge reuse process to compare it with the processes proposed by each study. This work has the originality to firstly formalize the Markus knowledge reuse process and extract from it a set of criteria to measure the efficiency of other knowledge management and reuse process. We then proposed a framework based on the result of the analysis of studies in order to improve knowledge management and reuse in online communities by the integration of automated techniques of knowledge extraction and capitalization. To the best of our knowledge, this is the first study of its kind. Future works will be conducted in the implementation of the proposed framework in a real online community in order to test the ability of the framework on the capitalization and the reuse of the human shared knowledge.

\section{$7 \quad$ Bibliography}

[1] Carr, A.M., Thamizoli, P., Rengalakshmi, R., \& Balasubramanian, K. (2018), "Learning through social media: a Promethean gift?" CSI Transactions on ICT, Vol. 6, pp. 301-310. https://doi.org/10.1007/s40012-018-0211-2

[2] Wenger E. (2001), "Supporting communities of practice: a survey of community-oriented technologies" Report to the Council of CIOs of the US Federal Government.

[3] Gray, B. (2004), "Informal Learning in an Online Community of Practice", Journal of Distance Education, Vol. 19 No. 1, pp. 20-35.

[4] Curran, J. A. et al. (2009), "Bridging the Gap: Knowledge Seeking and Sharing in a Virtual Community of Emergency Practice", Evaluation \& the Health Professions, Vol. 32 No. 3, pp. 314-327. https://doi.org/10.1177/0163278709338570

[5] Chin, A. and Chignell, M. (2007), "Identifying communities in blogs: roles for social network analysis and survey instruments", International Journal of Web Based Communities, Vol. 3 No. 3, p. 345. https://doi.org/10.1504/ijwbc.2007.014243

[6] Fulton, K.P., and Riel, M. (1999), "Professional Development through Learning Communities", available at: 
http://www.edutopia.org/php/article.php?id=Art_481\&key=238 (accessed 25 February 2019).

[7] Christensen, K., Liland, K.H., Kvaal, K., Risvik, E., Biancolillo, A., Scholderer, J., Nørskov, S., Næs, T. (2017) "Mining online community data: The nature of ideas in online communities", Food Quality and Preference, Vol. 62, pp. 246-256. https://doi.org/10.1016/j.foodqual.2017.06.001

[8] Davenport, T. \& Prusak, L. (1998). Working Knowledge. Harvard Business School Press. USA.

[9] Nonaka, I., Toyama, R., \& Konno, N. (2000). SECI, Ba and Leadership: A Unified Model of Dynamic Knowledge Creation. Long Range Planning: International Journal of Strategic Management, Vol. 33 No. 1, pp. 5-34. https://doi.org/10.1016/s0024-6301(99)00115-6

[10] Polanyi, M. (1958), Personal Knowledge, The University of Chicago Press, Chicago.

[11] De Lima, J.C., De Carvalho, C.L. and Ambrósio, A.P.L. (2010), "Knowledge Management in Virtual Communities of Practice", In Virtanen, P. and Helander, N. (Ed.), Knowledge Management, InTech, pp. 93-110. https://doi.org/10.5772/9553

[12] Berkani, L., Chikh, A. (2010), “A process for knowledge reuse in communities of practice of e-learning" in Procedia - Social and Behavioral Sciences, Vol. 2, No. 2, pp. 4436-4443. https://doi.org/10.1016/j.sbspro.2010.03.707

[13] Nonaka, I. and Takeuchi, H. (1995) The Knowledge-Creating Company: How Japanese Companies Create the Dynamics of Innovation. Oxford University Press, New York.

[14] Sandkuhl, Kurt (2015) Knowledge Reuse: Survey of Existing Techniques and Classification Approach Germany, July 6-11, 2014,

[15] Mihindu, S., Fernando, T., Khosrowshahi, F. (2008) Knowledge processing, codification and reuse model for communities of practice. In Johannesson, P., Arabnia, H.R. and Shahzad, M.K. (Ed) Special Issue: Information \& Knowledge Engineering, Ubiquitous Computing and Communication Journal, Jan 2008

[16] Markus, L. M. (2001), "Toward a Theory of knowledge reuse: types of knowledge reuse situations and factors in reuse success", Journal of Management Information Systems, Vol. 18 No. 1, pp. 57-93. https://doi.org/10.1080/07421222.2001.11045671

[17] Hord, S.M. (1997), Professional learning communities: Communities of continuous inquiry and improvement, Southwest Educational Development Laboratory, Austin, Texas.

[18] Berkani, L., Chikh, A. and Nouali, O. (2011), "semantics and knowledge capitalization in online communities of practice of e-learning", In Proceedings of the International Conference on Knowledge Management and Information Sharing (KMIS-2011), SCITEPRESS (Science and Technology Publications, Lda.), pp. 96-104. https://doi.org/10.5220/0003676500960104

[19] Wicaksono, A.F. and Myaeng, S.H. (2013), "Automatic extraction of advice-revealing sentences fo radvice mining from online forums", In Proceedings of the seventh international conference on Knowledge capture (K-CAP '13), ACM, New York, NY, USA, pp. 97-104. https://doi.org/10.1145/2479832.2479857

[20] Kim, K., Lee, S., Son, J. and Meeyoung, Cha, M. (2014), "Finding informative Q\&As on twitter", In Proceedings of the 23rd International Conference on World Wide Web (WWW '14 Companion), ACM, New York, NY, USA, pp. 319-320. https://doi.org/10.1145/2 $\underline{567948.2577291}$

[21] Chu, C.X., Tandon, N. and Weikum, G. (2017), "Distilling Task Knowledge from How-To Communities", In Proceedings of the 26th International Conference on World Wide Web (WWW '17), International World Wide Web Conferences Steering Committee, Republic and Canton of Geneva, Switzerland, pp. 805-814. https://doi.org/10.1145/3 $\underline{038912.3052715}$ 
[22] Jurafsky, D., Martin, J.H. (2009), Speech and Language Processing (2nd Edition). Prentice-Hall, Inc., Upper Saddle River, NJ, USA.

[23] Wenger, E., McDermott, R. A. and Snyder, W. (2002), Cultivating Communities of Practice: A Guide to Managing Knowledge, Harvard Business Press, Boston.

[24] Liddy, E.D. (2001), Natural Language Processing. In Encyclopedia of Library and Information Science, 2nd Ed. NY. Marcel Decker, Inc.

[25] Malik, Z., Hashmi, K., Najmi, E. and Rezgui, A. (2019) "Wisdom extraction in knowledge-based information systems", Journal of Knowledge Management, Vol. 23 No. 1, pp.23-45. https://doi.org/10.1108/jkm-05-2018-0288

[26] Rheingold, H. (1993), The Virtual Community: Homesteading on the Electronic Frontier, The MIT Press, Cambridge USA.

\section{Authors}

Houda Sekkal is a Ph.D. Candidate at the Laboratory of Research in Computer Science and Education, Mohammadia School of Engineers, Mohammed V University of Rabat, Morocco. My research project is about the use of knowledge management and data mining to improve the processus of learning in online learning communities. Email: houda.sekkal@gmail.com

Naila Amrous is a full professor at School of Information Sciences; $\mathrm{PhD}$ in Information and Communication Sciences; Ongoing research: Information literacy (IL), Knowledge Management (KM); Innovative Teaching practices. Email: amrousnaila@yahoo.fr

Samir Bennani is a Full Professor and Deputy Director of students and academic affairs at Mohammadia School of Engineers. Engineer degree in Computer Science in 1982; PhD in Computer Science in 2005; Professor at the Computer Science Department-EMI; 34 recent publications papers between 2014 and 2017; Ongoing research interests: SI, Modeling in Software Engineering, Information System, eLearning content engineering, tutoring, assessment and tracking. Email: sbennani@emi.ac.ma

Article submitted 2019-04-02. Resubmitted 2019-06-15. Final acceptance 2019-06-15. Final version published as submitted by the authors. 